\title{
CATALYTIC ACTION OF NITRIC ACID ON THE HYDROLYSIS OF ETS-40 ETHYL SILICATE
}

\author{
Iryna Lutsyuk ${ }^{1,}{ }^{凶}$, Yaroslav Vakhula ${ }^{1}$, Iryna Tupis ${ }^{1}$, Iryna Iliuchok ${ }^{1}$
}

https://doi.org/10.23939/chcht15.04.475

\begin{abstract}
The effect of concentrated nitric acid on the hydrolysis rate of ETS-40 ethyl silicate has been studied. The duration and maximum temperature of ethyl silicate hydrolysis at different temperatures of the components have been determined. The formation of silica particles in the xerogel structure is shown. The influence of the ETS40 hydrolysis on the particles size and concentration has been examined. The structure of the xerogel and the composition of the formed particles have been investigated using scanning electron microscopy (SEM) and energy dispersion analysis (EDX).
\end{abstract}

Keywords: ETS-40 ethyl silicate, hydrolysis, xerogel, silica particles.

\section{Introduction}

In recent years the scientific progress in all fields necessitates the development of new materials with high operating properties and functionalities. This, in turn, requires the improvement of existing and the development of new technologies.

One of the advanced technologies for obtaining silicate materials (ceramic powders of submicron sizes, thin-layer glass coatings, functional glass fibers and films) is sol-gel technology [1-3]. This technology involves the preparation of the sol of the required composition, a gradual increase in its viscosity with the formation of a homogeneous gel. Further use of the gel and corresponding modes of its processing are determined by the purpose of the final product. True or colloidal solution is used to obtain thin-layer glass coatings on metal, ceramics, etc. $[4,5]$. The dried gel allows to obtain powders of the required size, which, in turn, serve as a basis for the synthesis of ceramic products for technical purposes, composite medical materials, etc. [6, 7].

The advantages of sol-gel technology are a high homogeneity degree of the solution, the ability to control the particle size and chemical composition of the powder,

Lviv Polytechnic National University

12, Bandery St., Lviv, 79013, Ukraine

${ }^{\otimes}$ KhTS.dept@lpnu.ua

(C) Lutsyuk I., Vakhula Y., Tupis I., Iliuchok I., 2021 an avoidanceof the grinding stage and, most importantly, a significant reduction in energy costs. Materials for carrying out the sol-gel process are water-soluble salts or alkoxides of metals.

In the case of obtaining materials which contain silicon(IV) oxide, usually TEOS (ethyl ester of orthosilicic acid $\mathrm{Si}\left(\mathrm{OC}_{2} \mathrm{H}_{5}\right)$ ) or ETS of different composition (ethyl silicate, which is a mixture of orthosilicic acid esters derivatives with different molecular weight and molecular structure, ETS-32, ETS-40) are used. To obtain siliconcontaining colloidal solutions, these products are not usedin pure form. To transfer the prepared solutions from the sol to the gel, it is necessary to carry out their preliminary hydrolysis.

Analysis of numerous publications, in particular [8], on the production of organo-inorganic composite materials shows that tetraethoxysilane solutions in organic solvents (acetone, isopropyl alcohol, etc.)cause the greatest interest as the binders.

Commercial ethyl silicates, which are produced today, differ in the concentration of $\mathrm{SiO}_{2}$ and the amount of tetraethoxysilane introduced with the products of complete or partial polymerization/condensation. Therefore, to obtain high-quality solvent-free sol-gel composite materials, an individual approach to the hydrolysis of ethyl silicates is required.

Among the main factors that determine the processes of hydrolytic polycondensation and gelation of ethyl silicate gels are: $\mathrm{pH}$ of the medium, concentration and nature of the catalyst, as well as the ratio of ethyl silicate: water. In the alkaline medium the reaction rate directly depends on the alkali concentration; in the acid medium it depends on the catalyst concentration and type, which, in turn, determines the production of a certain gel structure [9].

The aim of this work is to study the kinetics of the hydrolysis reaction of ETS-40 in the medium of nitric acid and the selection of optimal conditions for obtaining the technological sol.

\section{Experimental}

The initial materials were ETS-40 (standard) and concentrated nitric acid of PA grade. The components 
were kept in a refrigerator at $275-278 \mathrm{~K}$ for $12 \mathrm{~h}$. Each component was weighed on an analytical weight with anaccuracy of $\pm 0.0001 \mathrm{~g}$.

The ethyl silicate hydrolysates were prepared in a thermally insulated closed beaker (volume $100 \mathrm{ml}$ ) under constant stirring using a laboratory magnetic stirrer. The hydrolysate temperature was recorded every $30 \mathrm{~s}$ with an accuracy of $\pm 0.1 \mathrm{~K}$ using a stationary thermometer installed in the beaker. Temperature measurements were stopped when the hydrolysate reached ambient temperature.

The morphology and structure of the gels fracture were studied using a ZEISS EVO 40XVP scanning electron microscope with an INCA Energy 350 detector. Surface images were obtained by recording secondary electrons by scanning with an electron beam $(20 \mathrm{keV})$.

The chemical composition of the particles was investigated by energy dispersion analysis (EDX).

The $\mathrm{pH}$ value of the sols was determined using an ionomer I-160MI.

Taking into account the influence of various factors on the ethyl silicate hydrolysis, as well as the mechanism and rate of polycondensation, the following conditions were adopted to obtain the sol.

Hydrolysis of ethyl silicate should be carried out in the presence of an acid catalyst at a ratio of $n \mathrm{H}_{2} \mathrm{O} / \mathrm{C}_{2} \mathrm{H}_{5} \mathrm{O}=3$ according to the reaction (1):

$\left(\mathrm{C}_{2} \mathrm{H}_{5} \mathrm{O}\right)_{4} \mathrm{Si}+3 \mathrm{H}_{2} \mathrm{O}=\mathrm{H}_{2} \mathrm{SiO}_{3}+4 \mathrm{C}_{2} \mathrm{H}_{5} \mathrm{OH}$

Concentrated nitric acid was used as an acid hydrolysis catalyst; its amount was $0.2-0.8 \mathrm{wt} \%$ relative to the total content of ethyl silicate and water, which provides $\mathrm{pH}$ of 1-2. Multicomponent gels are obtained on the basis of hydrolysate with the addition of nitrates of the corresponding metals. In this regard, nitric acid was used as a catalyst to ensure chemical anionic homogeneity. The $\mathrm{pH}$ value of the hydrolysate was 1.5-1.6 and did not change during the whole process.

The calculated amount of concentrated nitric acid was previously added to the distilled water, and the

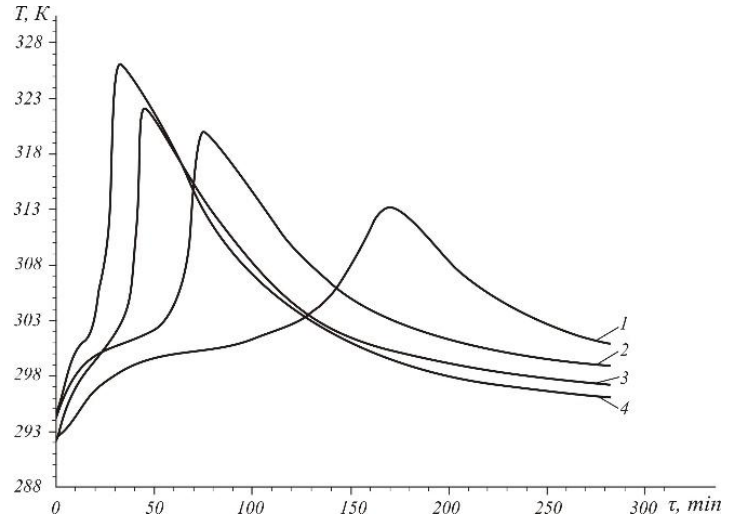

a) resulting solution was evenly added dropwise to ETS-40. Since ethyl silicate and water are mutually insoluble, and the hydrolysis reaction occurs only at the interface of the liquids, it is necessary to constantly stir the solution.

\section{Results and Discussion}

To determine the effect of temperature of the initial materials on hydrolysis process the components at room temperature (NP series) and the components cooled to 275-278 K (NO series) were used.

When $0.2 \%$ of $\mathrm{HNO}_{3}$ (NP series) is introduced into the system, the maximum temperature of $313 \mathrm{~K}$ is reached after 170 min (Fig. 1a). A further increase in the amount of acid catalyst to $0.8 \%$ leads to a significant intensification of the hydrolysis reaction, which is confirmed by further studies. The maximum hydrolysis reaction temperature increases, namely: $0.4 \%$ of $\mathrm{HNO}_{3}$ leads to the increase in temperature to $320 \mathrm{~K}$ (74 min), $0.6 \%$ - to $322 \mathrm{~K}(44 \mathrm{~min})$ and $0.8 \%$ - to $326 \mathrm{~K}$ (32 $\mathrm{min})$. It should be noted that due to hydrolysis, the system with $0.8 \%$ of $\mathrm{HNO}_{3}$ converts into a viscous state. Therefore, a further increase in the amount of acid catalyst for the hydrolysis of ethyl silicate was considered impractical.

It is known [3] that the increase in the hydrolysis time leads to the free rapid evaporation of volatile products, which ensures the purity of the gel, and in combination with the increase in hydrolysate temperature contributes to the aggregation of sol particles. Therefore, in order to obtain homogeneous solutions, it was decided to use components cooled to 275-278 K (NO series).

One can see (Fig. 1b), that the cooling of components provides the increase in time necessary to achieve the maximum hydrolysis temperature by $2-3$ times and reduce it by an average of $7-10 \mathrm{~K}$. The parameters of the hydrolysis process are given in Table 1.

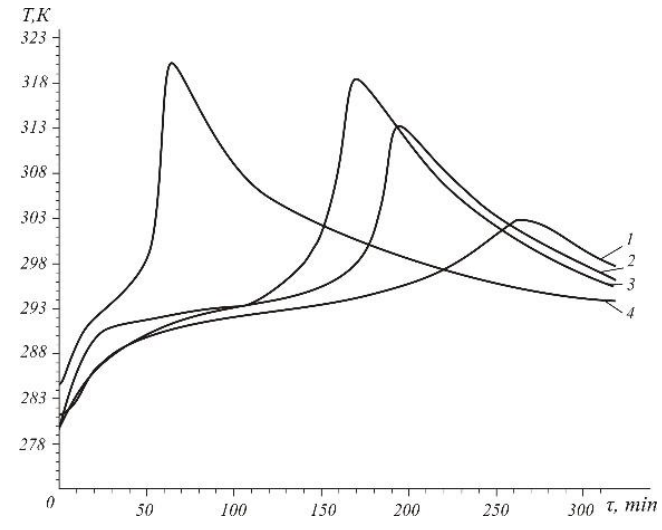

b)

Fig. 1.Hydrolysis kinetics of ETS-40 of NP series (a) and NO series (b) with different amount of concentrated $\mathrm{HNO}_{3}$, wt \%:0.2 (1); 0.4 (2); $0.6(3)$ and 0.8 (4) 
Parameters of ETC-40 hydrolysis

\begin{tabular}{|c|c|c|c|c|}
\hline Symbol & $\begin{array}{c}\mathrm{HNO}_{3} \text { amount, } \\
\text { wt } \%\end{array}$ & $\begin{array}{c}\text { Temperature of the initial } \\
\text { compounds, } \mathrm{K}\end{array}$ & $\begin{array}{c}\text { Maximal temperature of } \\
\text { hydrolysis, } \mathrm{K}\end{array}$ & $\begin{array}{c}\text { Time for achieving maximal } \\
\text { temperature, min }\end{array}$ \\
\hline NP1 & 0.2 & \multirow{3}{*}{$291-293$} & 313 & 170 \\
\hline NP2 & 0.4 & & 320 & 74 \\
\hline NP3 & 0.6 & & 322 & 44 \\
\hline NP4 & 0.8 & & 326 & 32 \\
\hline NO1 & 0.2 & \multirow{4}{*}{$275-278$} & 303 & 260 \\
\hline NO2 & 0.4 & 313 & 195 \\
\hline NO3 & 0.6 & & 318 & 170 \\
\hline NO4 & 0.8 & & 320 & 65 \\
& & & \\
& & & \\
\hline
\end{tabular}

Additional information on the kinetics of ETS condensation according to the selected modes is given by the results of SEM analysis. When examining the fresh fracture surface of all xerogels one can see that amorphous particles of various sizes of indeterminate shape are observed against the background of the matrix gel.

EDX analysis was used to determine the content of elements in the formed particles. Thus, it was established (Fig. 2, spectrum 1) that the composition of the specified particle includes silicon and oxygen (Table in Fig. 2). The obtained data allow to assert that each particle consists of silica $-\mathrm{SiO}_{2}$.

To establish the effect of the initial components temperature on the main parameters of silica particles, we carried out a comparative analysis of xerogel samples obtained by components hydrolysis at room temperature (NP series samples) and cooled to 275-278 K (NO series samples).

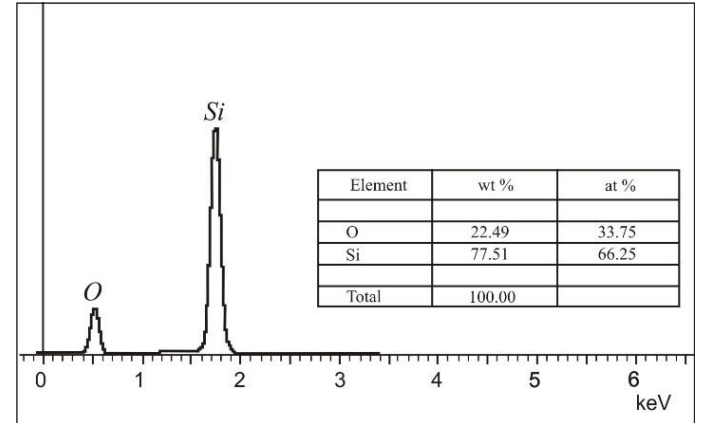

Fig. 2. Elemental analysis of the particles in the xerogel structure

Studies have shown that changes in the concentration of nitric acid have a significant effect on both the size of individual particles and their number in individual areas. The number of particles was counted visually at the places of their maximum allocation on the area of $100 \mu \mathrm{m}^{2}$.

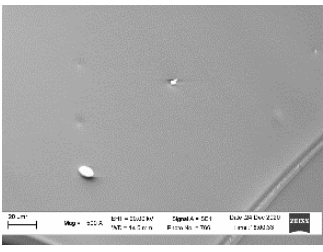

a)

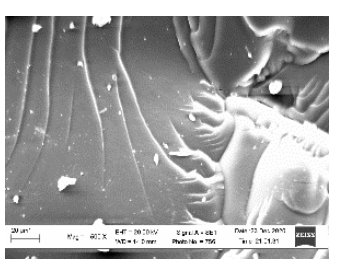

a)

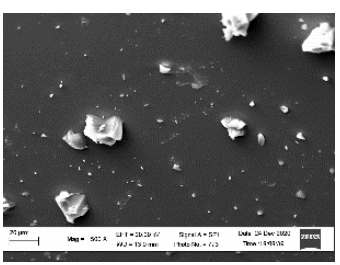

b)

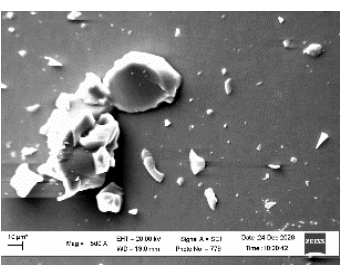

b)

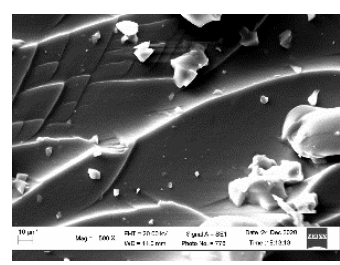

c)

NO series

Fig. 3. Structure of fresh fracture of xerogel with $\mathrm{HNO}_{3}$ amount of (wt \%): 0.2 (a); 0.4 (b); 0.6 (c) and 0.8 (d)

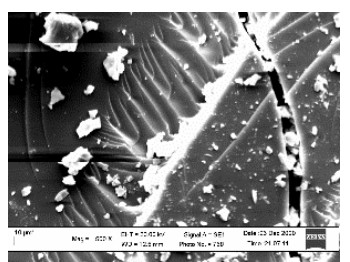

c)

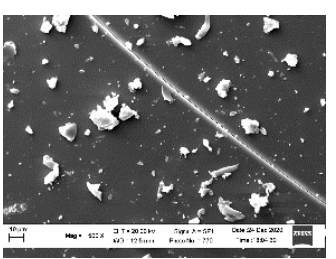

d)

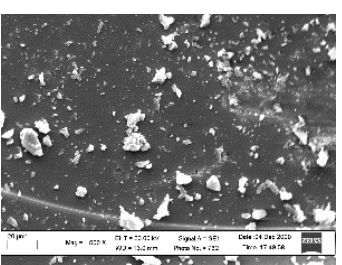
d) 
Table 2

\begin{tabular}{|c|c|c|c|}
\hline Symbol & Amount of $\mathrm{HNO}_{3}, \mathrm{wt} \%$ & Number of particles, units & Particles size, $\mu \mathrm{m}$ \\
\hline NP1 & 0.2 & 1 & 10 \\
\hline NP2 & 0.4 & $2-4$ & $0.1-5$ \\
\hline NP3 & 0.6 & $5-7$ & $1-20$ \\
\hline NP4 & 0.8 & $6-7$ & $0.5-15$ \\
\hline NO2 & 0.2 & $4-5$ & $1-15$ \\
\hline NO3 & 0.4 & $6-7$ & $1-10$ \\
\hline NO4 & 0.6 & $6-9$ & $0.5-8$ \\
\hline
\end{tabular}

With $\mathrm{HNO}_{3}$ amount of $0.2 \mathrm{wt} \%$ (Fig. 3a) allocation of siliceous particles is practically not observed (only some of them are visible). The increase in $\mathrm{HNO}_{3}$ amount to 0.4 and $0.6 \mathrm{wt} \%$ causes the appearance of a greater number of particles. Their size is mainly $2-5 \mu \mathrm{m}$, although some of them reach $20 \mu \mathrm{m}$. Their concentration increases (Table 2).

The number of particles increases sharply in the presence of $0.8 \mathrm{wt} \%$ of $\mathrm{HNO}_{3}$ (Fig. 3d). Their size ranges from 0.5 to $15 \mu \mathrm{m}$ and their number in some areas is 6-7 units.

The introduction of even $0.2 \mathrm{wt} \%$ of $\mathrm{HNO}_{3}$ into the cooled solution provides the formation of $\mathrm{SiO}_{2}$ particles with the size of $1-15 \mu \mathrm{m}$; their number is $4-5$ units (Fig. 3b).

Further increase in the $\mathrm{HNO}_{3}$ amount leads to a sharp increase in the number of particles, and at $0.8 \mathrm{wt} \%$ their number is almost twice (11-12 units) as high as for similar solution of the NP series. The size of most particles decreases to $0.5-2 \mu \mathrm{m}$.

\section{Conclusions}

The amount of acid catalyst was found to be an important and effective factor influencing the hydrolysis rate of ETS-40 ethyl silicate. Thus, when the amount increases from 0.2 to $0.8 \mathrm{wt} \%$, the hydrolysis rate decreases by $3-5$ times. Cooling of the components leads to the increase in hydrolysis time and the decrease in the maximum temperature. Silica particles were found in the xerogel structure against the background of the matrix. Their size and number depends on the nitric acid amount and was found to be $0.5-10 \mu \mathrm{m}$. The highest number of particles was observed when using cooled components and $\mathrm{HNO}_{3}$ amount was $0.8 \mathrm{wt} \%$.

To obtain a hydrolysate with a low gelation rate, the amount of concentrated $\mathrm{HNO}_{3}$ in the system should be in the range of $0.4-0.6 \mathrm{wt} \%$ with pre-cooling of the initial components.

\section{References}

[1]Sajjadi S.: J. Polym. Eng. Technol., 2015,13, 38. http://polymer.aut.ac.ir/

[2] Lutsyuk I., Vakhula Ya.: Chem. Chem. Technol., 2018, 12, 386.https://doi.org/10.23939/chcht12.03.386

[3] Bertolini M., Zaghete M., Gimenes R., Paiva-Santos C.: Mater. Lett., 2005, 59, 3196. https://doi.org/10.1016/j.matlet.2005.04.054

[4] Skroznikova V., Popovich N., Dimitrov Ts.:Nauchni Trudove na Rusenskia Universitet, 2013, 52, 61 .

[5] Vakhula Ya., Vasijchuk V., Romaniv A., Semchuk O.:Chem. Chem. Technol., 2007, 1, 103.

[6] Maeda H., Nakano Y., Kasuga T.: J. Nanomater., 2013, 2013, 1064.https://doi.org/10.1155/2013/463048

[7] Adams L., Essien E., Shaibu R., Oki A.: New J. Glass Ceram. 2013, 3, 11.https://doi.org/10.4236/njgc.2013.31003

[8] SkorodumovaO., TarakhnoO., GoncharenkoD., ShubaI.:

KeramichniKompozytsyiniMaterialyiVognestiikiPokryttianaOsnovi HybrydnykhGeliv. FOPPanova, Kharkiv 2017.

[9] SemchenkoG.: Zol-GelProcess v Keramicheskoi Technologii. Kharkov 1997.

Received: January 12, 2021 / Revised: April 13, 2021 / Accepted: February 02, 2021

\section{КАТАЛІТИЧНА ДІЯ НІТРАТНОЇ КИСЛОТИ НА ГІДРОЛІЗ ЕТИЛСИЛІКАТУ ЕТС-40}

Анотація. Досліджено вплив концентрованої нітратної кислоти на швидкість гідролізу етилсилікату ЕТС-40. Визначено тривалість і максимальну температуру гідролізу етилсилікату за різної температури компонентів. Показано утворення кремнеземистих частинок в структурі ксерогелю. Вивчено вплив особливостей проведення гідролізу ЕТС-40 на розмір $i$ кониентрачію частинок. Структуру ксерогелю та склад утворених частинок досліджено за допомогою електронно-мікроскопічного (CEM) та енергодисперсійного аналізів (EDX).

Ключові слова: етилсилікат ЕТС-40, гідроліз, ксерогель, кремнеземисті частинки. 